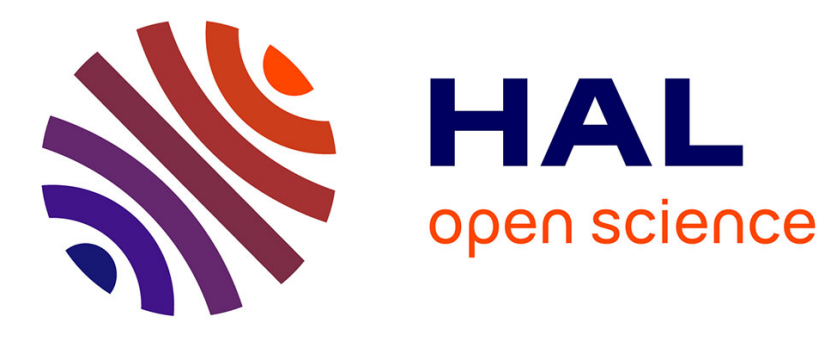

\title{
Atomic-Insight into Zeolite Catalyst Forming-an Advanced NMR Study
}

Louwanda Lakiss, Cassandre Kouvatas, Jean-Pierre Gilson, Valentin Valtchev, Svetlana Mintova, Christian Fernandez, Robert Bedard, Suheil Abdo, Jeffery Bricker

\section{To cite this version:}

Louwanda Lakiss, Cassandre Kouvatas, Jean-Pierre Gilson, Valentin Valtchev, Svetlana Mintova, et al.. Atomic-Insight into Zeolite Catalyst Forming-an Advanced NMR Study. Journal of Physical Chemistry C, 2021, 125 (36), pp.20028-20034. 10.1021/acs.jpcc.1c05501 . hal-03423491

\section{HAL Id: hal-03423491 \\ https://hal.science/hal-03423491}

Submitted on 10 Nov 2021

HAL is a multi-disciplinary open access archive for the deposit and dissemination of scientific research documents, whether they are published or not. The documents may come from teaching and research institutions in France or abroad, or from public or private research centers.
L'archive ouverte pluridisciplinaire $\mathbf{H A L}$, est destinée au dépôt et à la diffusion de documents scientifiques de niveau recherche, publiés ou non, émanant des établissements d'enseignement et de recherche français ou étrangers, des laboratoires publics ou privés. 


\title{
Atomic-Insight into Zeolite Catalyst Forming—an Advanced NMR Study
}

\author{
Louwanda Lakiss, $\dagger^{* *}$ Cassandre Kouvatas, $\dagger^{* *} J e a n-P i e r r e ~ G i l s o n \dagger^{*}$, Valentin Valtchev, $\dagger$ \\ Svetlana Mintova, $\uparrow$ Christian Fernandez, †Robert Bedard, $\neq$ Suheil Abdo, $\ddagger$ Jeffery \\ Bricker
}

† Normandie Univ, ENSICAEN, UNICAEN, CNRS, Laboratoire Catalyse et Spectrochimie, 14000 Caen, France

‡ UOP LLC, 25 East Algonquin Road, Des Plaines, IL 60016, USA

\begin{abstract}
The main goal of this study is to understand, at the atomic level, the chemical interactions occurring between an active phase, a FAU zeolite in this case, and its binder during catalyst forming. This unit operation is a critical step in catalyst scale-up and commercialization but hasn't received the attention it deserves from academia. Herein, we present atomic-level insight in the solid-state chemistry taking place during the extrusion process by advanced NMR spectroscopy techniques (Indirect ${ }^{27} \mathrm{Al}\left\{{ }^{1} \mathrm{H}\right\} \mathrm{DNP}$ MAS and ${ }^{27} \mathrm{Al}-\left\{{ }^{29} \mathrm{Si}\right\} \mathrm{J}-\mathrm{HMQC}$ ). In particular, we: i) elucidate the chemical reactions taking place between atype $\mathrm{Y}$ FAU zeolite $(\mathrm{Si} / \mathrm{Al}=\mathbf{2 . 3}$ ) and abinder (pseudoboehmite), producing new active sites different than those present in either the zeolite or binder, ii) determine the location of these new active sites by a combination of DNP build-up time (TDNP)extracted from $\left\{{ }^{1} \mathrm{H}\right\}-{ }^{27} \mathrm{Al}$ saturation-recovery $\mathrm{CP}$ experiments and $2 \mathrm{D}$ heteronuclear ${ }^{29} \mathrm{Si}-{ }^{27} \mathrm{Al} \mathrm{NMR}$. This illustrates the power of advanced NMR techniques to elucidate the nature and location of newly created active sites during catalyst forming and provides insight into a key step to further fine-tune industrial catalysts.
\end{abstract}

\section{Introduction}

Forover 60 years, zeolites have been used in numerous industrial processes such as separation, purification, adsorption and catalysis. 1,2,3,4,5,6 Industrial zeolite catalysts generally differ from their laboratory prototypes as they have to meet other requirements such as crushing strength, abrasion resistance, heat transfer, minimal pressure drop and diffusion resistance, deactivation rate and ease of regeneration. These requirements, in turn, determine the shape and form of the catalyst loaded in industrial reactors and add an important binding step in zeolitic catalyst and adsorbent manufacturing. Up to now, a limited number of studies investigated the impact of forming on the performance of zeolite catalysts. ${ }^{7,8,9,10,11}$

During forming, zeolites are dispersed in inorganic matrices such as silica, alumina, clays, and selection of the appropriate forming process (extrusion, pelletizing, spray-drying, oil dropping) depends strongly on the process requirements described above. ${ }^{8}$ Silica and alumina remain the most commonly used binders due to their favorable cost to performance ratio and well-known efficacy. It is already recognized that they do not always act as inert diluents, and they might impact positively or negatively the catalytic performance of the shaped bodies, but published literature related to the understanding ofthe atomic-scale interactions that take place at the interface has been sparse.

Recently, Seghers et al. reported a significant improvement of catalyst lifetime upon forming in the Diels Alder reaction to prepare bicyclic norbornene scaffolds from cyclopentadiene and methyl acrylate. ${ }^{12}$ Gascon et al. spray-dried ZSM-5/clay catalysts and showed that the nature of the clay modifies their acidity and affects the catalytic performances in the methanol-to-olefins (MTO) reaction, in particular, the alkene and arene selectivity. ${ }^{13}$ Michels et al. also investigated the impact of binding on hierarchical ZSM-5 catalysts onthe MTO reaction; in particular, they noticed that binding with attapulgite provided the highest catalyst stability and light olefin selectivity, but no correlation was observed between improved performance and acidity. ${ }^{14}$

Numerous techniques such as Raman and infrared micro-spectroscopies, magnetic resonance imaging, Xray absorption, and diffraction microtomography (micro-CT) have been recently used to visualize shaped zeolite catalysts at the macro- and nano-scales with spatio temporal resolution. ${ }^{15,16,17,18}$ For instance, fluorescent nanoprobes were used to detect and identify the active phase (zeolite $Y$ ) in fluid catalytic cracking catalysts using confocal laser scanning microscopy (CLSM). ${ }^{19}$ Michels et al. followed an integrated approach to visualize hierarchical zeolite technical bodies by combining optical, X-ray, electron microscopy, and tomographic techniques. ${ }^{20}$ Although, these approaches are very useful to visualize the textural features and 
pores architecture of shaped catalysts, they do not provide atomic-level details of thezeolite binder interfacesuponforming.

Previously, we investigated the chemical interactions between a zeolite and its alumina binder by IR spectroscopy of adsorbed basic probes such as pyridine and C0. ${ }^{11}$ We demonstrated the formation of new acid sites after extrusion, reminiscent of amorphous silica-aluminas. The shaped extrudates also showed high catalytic performance in the dealkylation of 1,3,5-Triisopropylbenzene, a bulky molecule that diffuses only with great difficulty through the microporosity. Such a result indicates that the newly created catalytic sites are not located in the zeolite micropores but most probably near their external surface. We now report the use of advanced NMR techniques to selectively investigate the zeolite-binder interface of extrudates at the atomic level to probe the chemical nature of this interface, as well as the internuclear interactions that occur.

Classical Solid-State Magic Angle Spinning NMR (SS MAS NMR) is already a proven and powerful technique to provide such chemical and structural atomic level information. For instance, it discriminates between different crystallographic framework positions in zeolite frameworksand detects the presence of extraframework cations. Unfortunately, NMR is a bulk technique probing all atoms, and therefore, a dedicated analysis of the external surface of zeolites is impossible as the related signals are overwhelmed by those intheir internal surface. The recently developed Dynamic Nuclear Polarization (DNP) enhancement overcomes such a limitation and appears a potentially ideal technique to investigate chemistry at surfaces and interfaces.

DNP-enhanced MAS NMR is increasinglyused to enhance the sensitivity in solid-state MAS NMR. The studied solid is first impregnated with a free radical solution acting as a paramagnetic polarization agent (PA) and then cooled to a cryogenic temperature. The polarization of the unpaired electron of these radicals is then transferred directly by microwave irradiation to nuclei surrounding the PA, the so-called direct DNPenhanced MAS NMR. Such transfer can also be mediated by ${ }^{1} \mathrm{H}$; in this case, the polarization of unpaired electrons is first transferred (from the solvent or the solid surface) to ${ }^{1} \mathrm{H}$ nuclei near the PA, then to other nuclei by classical Cross Polarization (CP) techniques. This so-called indirect DNP relies on transferring the ${ }^{1} \mathrm{H}$ polarization across the sample by spin diffusion. Lesage et al. used indirect DNP $C P{ }^{13} \mathrm{C}\left\{{ }^{1} \mathrm{H}\right\}$ to detectorganic species grafted on the surface of nanoporous silica. ${ }^{21}$ Direct and indirect DNP were used in synthetic clays to distinguish between $\mathrm{Si}$ atoms close to the radicals from those further away from the surface by ${ }^{1} \mathrm{H}$ spin diffusion and CP. ${ }^{22}$ Lee et al. demonstrated the selective enhancement of the first surface layer of $\gamma$-alumina catalysts by indirect DNP ${ }^{27} \mathrm{Al}\left\{{ }^{1} \mathrm{H}\right\}$ CP NMR. ${ }^{23}$ Mais et al. observed surface pentahedral aluminum in gammaalumina by indirect DNP. ${ }^{24}$

DNP NMR can also probe the porosity and nanostructure of materials based on the reduction of relaxation time of species near paramagnetic centers and spin diffusion. Schagnitweit et al. explored the combination of these effects to investigate the domain size of a component in an organic multicomponent mixture. ${ }^{25}$ Pinon et al. showed that DNP can probe the porosity of mesoporous silica materials via selective doping with paramagnetic species. ${ }^{26}$

The demonstrated high sensitivity of DNP and its ability to probe surfaces selectively makes it a tool of choice to investigate the zeolite/alumina interface, accessible to bulky PA molecules, of shaped bodies in general and catalysts in particular.

\section{Experimental section}

\section{Materials and Preparation}

A Y zeolite with a $\mathrm{Si} / \mathrm{Al}$ ratio of 2.3 (LZY-64 supplied by UOP) is used throughout this work. Zeolite/alumina extrudates (dry mass ratio of $30 \mathrm{wt} \%$ zeolite and $70 \mathrm{wt} \%$ binder) are prepared as described earlier: ${ }^{11}$ the zeolite powder, Methocel (F4M, Dow Chemicals), and alkali-free pseudo-boehmite (Catapal B) are mixed and homogenized. Deionized water is then added dropwise to the solid mixture to obtain dough ready for extrusion. The dough is then transferred to a hand extruder (Makin's USA Professional Ultimate Clay Gun Extruder, $1.6 \mathrm{~mm}$ diameter die) for forming. The green extrudates are dried at $323 \mathrm{~K}$ for 2 hours in a convection oven and thereafter transferred to a muffle oven forcalcination as follows: i) $363 \mathrm{~K}$ for 12 hours ii) $823 \mathrm{~K}$ for 4 hours with a heating rate of $5 \mathrm{~K} / \mathrm{min}$. The calcined extrudates are then gently crushed, sieved, and the 200-500 $\mu \mathrm{m}$ fraction retained. For comparative purposes, the pristine zeolite and pseudobohemiteare heated under identical conditions. The physico-chemical properties of the parent zeolite, alumina binder, and alumina/zeolite extrudates were already reported elsewhere. ${ }^{11}$

\section{NMR Characterization}

DNP experiments are carried outon an $800 \mathrm{MHz}$ Bruker AvanceIII spectrometer operating at a Larmor Frequency of $800.13 \mathrm{MHz}\left({ }^{1} \mathrm{H}\right), 208.49 \mathrm{MHz}\left({ }^{27} \mathrm{Al}\right)$ and $158.96 \mathrm{MHz}\left({ }^{29} \mathrm{Si}\right)$ equipped with a 9.7T gyrotron 
magnet to generate microwaves, operating at $263 \mathrm{MHz}$.TEKPol, the radical source diluted in a 1,1,2,2tetrachloroethane (TCE), is impregnated by incipient wetness for DNP experiments. The TEKPol concentration is $40-50 \mathrm{mmol} / \mathrm{g}$ of zeolite/binder composite. All samples are packed into $3.2 \mathrm{~mm}$ zirconium rotors, frozen $(\mathrm{T} \sim 100 \mathrm{~K})$ inside a low-temperature $3.2 \mathrm{~mm}$ CPMAS probe head, and spun at $12 \mathrm{kHz}$ under a flow of nitrogen.

For indirect DNP, ramped CPMAS is used to transfer polarization from ${ }^{1} \mathrm{H}$ to ${ }^{27} \mathrm{Al}$ nuclei, under SPINAL64 ${ }^{1} \mathrm{H}$ decoupling during the acquisition. ${ }^{27} \mathrm{~A}$ low-power ${ }^{27} \mathrm{Al}$ radiofrequency field isused to ensure an efficient spinlocking of the quadrupolar nucleus, and thus the CP processes with a contact time of 0.7 ms. Recycle delays in the indirect ${ }^{27} \mathrm{Al}$ experiments are longer than 1.3 times $\mathrm{T}_{\mathrm{DNP}}$ measured in $\mathrm{CP}$ saturation-recovery experiments.

The DNP build-up times ( $\mathrm{T}_{\mathrm{DNP}}$ ) under microwave irradiation are measured ina saturation-recovery experiment, with a saturation pulse train before the variable polarization time (delay), followed by the ramped ${ }^{27} \mathrm{Al}\left\{{ }^{1} \mathrm{H}\right\} \mathrm{CP}$. Prior to all NMR experiments, the samples are partially dehydrated in a conventional oven at $473 \mathrm{~K}$ overnight.

\section{Discussion}

\section{General Characterization}

As described elsewhere ${ }^{11}$ zeolite $\mathrm{Y} / \gamma-\mathrm{Al}_{2} \mathrm{O}_{3}$ extrudates were already characterized by multiple conventional techniques. While the crystallinity of the calcined zeolite Y and its derived extrudates determined by XRD decreased to about $70 \%$ (Figure S1 in the Supporting information), the Brønsted acid sites (BAS) concentration in the extrudates wasslightly higher than in the parent zeolite. Furthermore, CO adsorption monitored by IR spectroscopy detected the presence of a new type of acid sites in addition to those of the pristine zeolite and alumina. The catalytic performance of the extrudates was evaluated in the dealkylation of 1,3,5 Tri-isopropyl benzene (TiPBz), a bulky reactant (kinetic diameter $=0.95 \mathrm{~nm}$ ), reaching only the external and mesoporous zeolite surfaces (Figure S2 in the Supporting information). The extrudates were significantly more active than physical mixtures of identical amounts of zeolite and $\gamma-\mathrm{Al}_{2} \mathrm{O}_{3}$. The conclusion is, of course, that the additional acidity created during extrusion is located at the interface between the zeolite and its binder and not in the micropores of the zeolite.

In this study, the aim of the DNP enhanced MAS NMR experiments is to validate the previous conclusions and shed light on atomic level features of the zeolite-binder interface interactions, as the selected TEKPol radicals (kinetic diameter $=2 \mathrm{~nm}$ ) used to generate the DNP signals do not penetrate the zeolite micropores ( $0.7 \mathrm{~nm}$ restricted openings of $1.13 \mathrm{~nm}$ supercages).

\section{Inventory of aluminum sites}

The aluminum sites located in the zeolite micropores and near PA's at the interface with the binder can be discriminated by comparing ${ }^{27} \mathrm{Al}$ MAS NMR with indirect $\left\{{ }^{1} \mathrm{H}\right\}{ }^{-27} \mathrm{Al}$ DNP MAS NMR. Figure 1 shows the ${ }^{27} \mathrm{Al}$ NMR spectra of the extrudates after partial dehydration (Figure 1a), the pure zeolite powder (Figure 1b) and the $\gamma$-alumina binder (Figure 1c) treated under identical conditions. Three types of peak are present on the extrudates, namely: i) 0 ppm: octahedral Al belonging either to the alumina binder or extra-framework zeolite aluminum; they are also present in the spectra of the pure zeolite powder and alumina treated under identical conditions ii) 75 and 65 ppm: the first assigned to tetrahedral aluminum in $\gamma$-alumina and the second to tetrahedral aluminum in the zeolite framework ${ }^{28}$ iii) 38 ppm: this weak and broad signal corresponds to pentahedral or distorted tetrahedral aluminum species. A linear combination analysis of the three spectra is presented in Figure S3. Data of this analysis are reported in Table S1 and Table S2. The integrated intensities of the extrudate spectrum indicate a proportion of $74.4 \%$ alumina and $25.6 \%$ zeolite, which is quite close to the mass proportion in the mixture. 


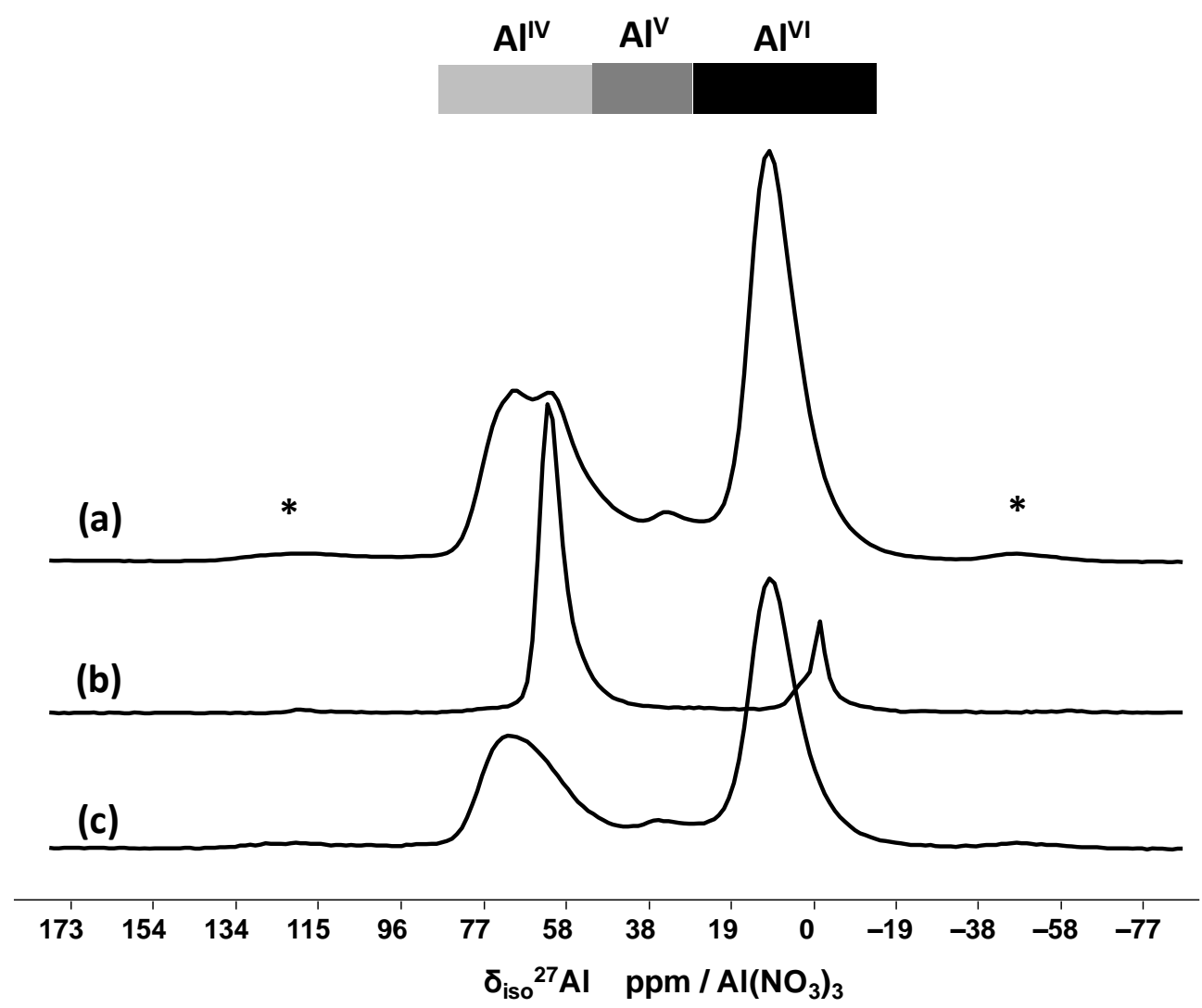

Figure $1{ }^{27} \mathrm{Al}$ MAS NMR spectra of (a) zeolite Y/alumina extrudates, (b) pure zeolite powder, (c) pure alumina. Spinning side bands are labelled with asterisks. The typical range observed for tetrahedral, pentahedral and octahedral aluminum sites is reminded on the top.

Indirect ${ }^{27} \mathrm{Al}\left\{{ }^{1} \mathrm{H}\right\}$ DNP MAS NMR selectively probes Al species near the PA's, i.e., close or at the zeolite-binder interface as it relies on spin diffusion spreading the polarization of the proton to Al by CP over the whole sample:

$\mathrm{e}-(\mathrm{PA}) \rightarrow{ }^{1} \mathrm{H}\left(\right.$ solvent or sample) $\rightarrow{ }^{27} \mathrm{Al}$ (sample) (1)

Figure 2 shows the indirect ${ }^{27} \mathrm{Al}\left\{{ }^{1} \mathrm{H}\right\}$ DNP NMR spectra of the: (a) alumina binder (b) zeolite powder (c) zeolite/alumina extrudates with microwave irradiation on and off. 

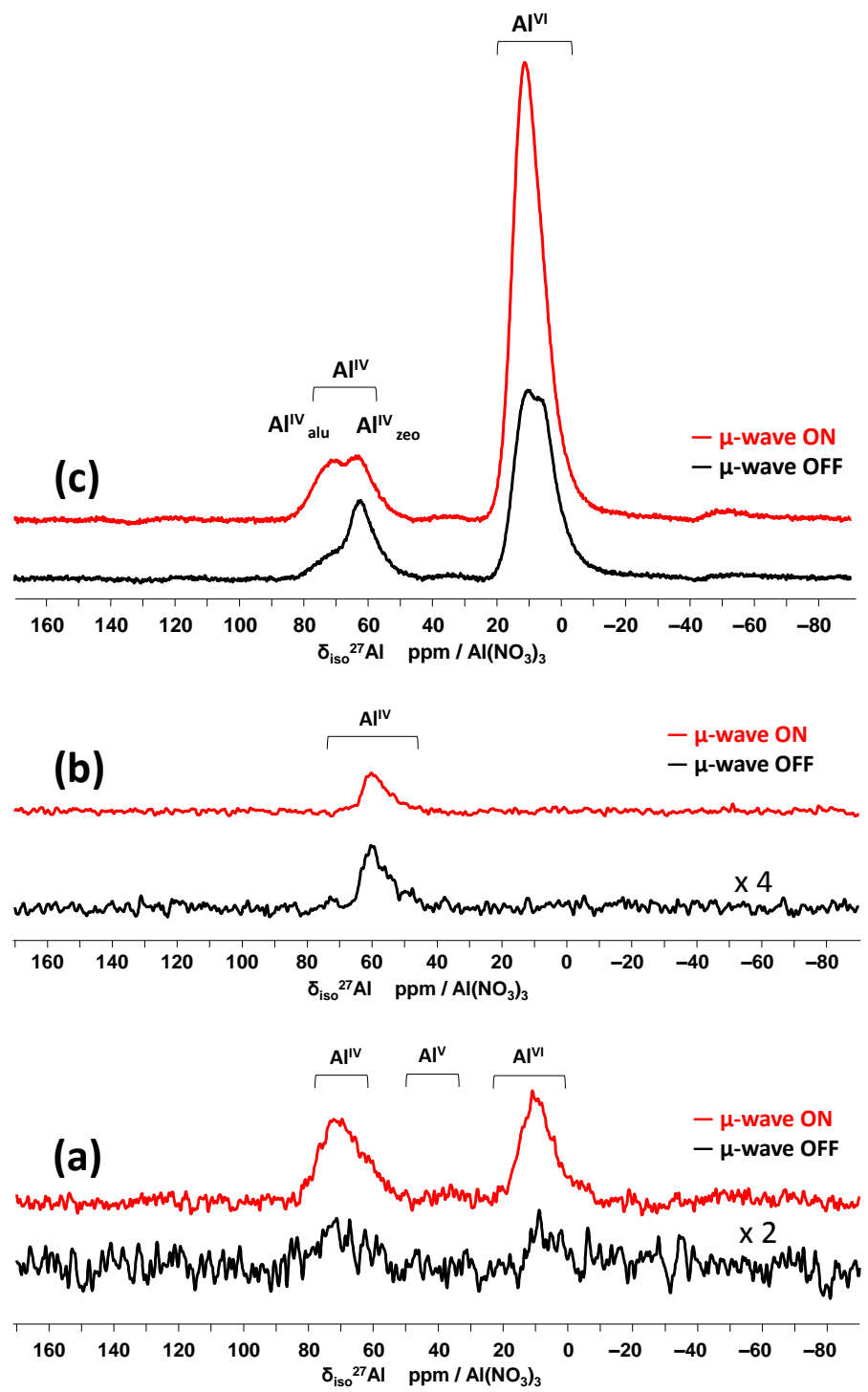

Figure 2.27 Al DNP-CP MAS NMR spectra with microwave ON (red) and OFF (black) of (a) pure $\gamma$-alumina, (b) pure Y zeolite powder and (c) zeolite Y/alumina extrudates. In 2a, the $\mu$-wave off spectrum is recorded with less scans than the $\mu$-wave on spectrum ( 32 vs 64 ), but the intensity adjusted (x2). An additional figure with the same amount of scan (16) is presented in SI (Figure S4). In Figure $2 \mathrm{~b}$, the $\mu$-wave off spectrum is recorded with 4 times less scans than $\mu$-wave on spectrum (64 versus 256 ), but the intensity is adjusted (x 4).

All spectra, with or without microwave irradiation, are similar, but their intensity increases under microwave irradiation, indicating a close proximity with the PA. The PA is too bulky to enter the zeolite microporosity, but the binder mesoporosity is accessible. The signal enhancement observed under microwave irradiation at $65 \mathrm{ppm}$ on the pure zeolite (Figure $2 \mathrm{~b}$ ) should therefore correspond only to tetrahedrally coordinated aluminum located on its external surface. Likewise, as no peak appears around 0 ppm under microwave irradiation, all the octahedrally coordinated aluminum (EFAL) detected without microwave irradiation should be located in the zeolite microporosity. On the extrudate spectrum, under microwave irradiation (Figure 2c), the broad signal between 0-10 ppm belongs to octahedrally coordinated Al from the binder while the signals in the tetrahedral region (50-80 ppm) are attributed to $\mathrm{Al}^{\mathrm{IV}}$ from the binder (77 ppm) and the external surface of the zeolite $(64 \mathrm{ppm})$, i.e., close to the zeolite/binder interface. Further information, such as the proximity of aluminum species, can be provided by measuring the DNP build-up time, $\mathrm{T}_{\mathrm{DNP}}$.

\section{Spatial insights on aluminum sites proximity}

The proximity of the above aluminum species can providecomplementary information on the binder/zeolite interface by measuring their respective $\mathrm{T}_{\text {DNPin }}$ an indirectDNP ${ }^{27} \mathrm{Al}\left\{{ }^{1} \mathrm{H}\right\}$ saturation recovery CP experiment. 
The saturation recovery part of this experiment focuses on analyzingthe $\mathrm{T}_{1}$ relaxation times asspecies close to the PA relax faster,i.e., have lower $\mathrm{T}_{1}$,leading to a so-called paramagnetic relaxation enhancement. Thenet result for zeolites is thatthe $\mathrm{T}_{\mathrm{DNP}}$ of their ${ }^{27} \mathrm{Al}$ atomslocated on or near theirexternal surface is shorter than those in the micropores.

The TDnptime constant depends on the DNP enhancement, quenching of the signal (loss due to the fast relaxation of species close to radicals), and spin diffusion,expressed in thefollowing stretched exponential function: ${ }^{29,30,31}$

$$
I=I_{0}\left(1-\exp \left(-\left(\frac{t}{T_{D N P}}\right)^{\beta}\right)\right)
$$

where $I_{0}$ is the maximal signal intensity and $\beta$ the stretching coefficient.This function is characteristic of a distribution of relaxation times $\mathrm{T}_{\mathrm{DNP}}$. The smaller $\beta$ is, the wider the distribution.

The intensity for every aluminum peak is extracted from each slice of the indirect DNP ${ }^{27} \mathrm{Al}\left\{{ }^{1} \mathrm{H}\right\}$ saturation recovery CP experiment.The resulting build-up curves from the signal intensities are then fitted to extract the $\mathrm{T}_{\mathrm{DNP}}$ of each aluminum(Table 1).For the pure zeolite, the only $\mathrm{T}_{\mathrm{DNP}}$ isfor tetrahedral aluminum $(2.0 \mathrm{~s})$ as no octahedral aluminum is present on its external surface,vide supra. On thepure alumina, the $\mathrm{T}_{\mathrm{DNP}}$ of tetrahedral and octahedral aluminumare $4.9 \mathrm{~s}$ and $4.3 \mathrm{~s}$, respectively. On the zeolite Y/alumina extrudate, $\mathrm{T}_{\mathrm{DNP}} \mathrm{s} 4.8 \mathrm{~s}$ and $5.5 \mathrm{~s}$ for tetrahedral and octahedral aluminum in the alumina binder and $6.9 \mathrm{~s}$ for the zeolitic tetrahedral aluminum. Thetetrahedral aluminum $\mathrm{T}_{\mathrm{DNPO}}$ of the extruded zeolite is therefore about three times longer than in the pure zeolite powder,while thetetrahedral and octahedral $\mathrm{T}_{\mathrm{DNP}}$ of alumina in extrudates are not significantly affected.

This highlights a spatial organisation in the extrudates between zeolite (further from the surface, as a core) and $\gamma$-alumina (closer to the surface), in addition to the physical spatial proximity between the two phases. The emerging picture is that on the external surface of pure zeolite $\mathrm{Y}$, only tetrahedral aluminum and Si are present, and in the extrudates, they interact with tetrahedral and octahedral aluminum from the alumina binder.The key question is the exact nature of the interaction at the zeolite/alumina interphase. Namely, which aluminum from the alumina (tetrahedral or octahedral) interacts with the zeolite external surface?A two-dimensional ${ }^{27} \mathrm{Al}-\left\{{ }^{29} \mathrm{Si}\right\} \mathrm{J}$-HMQCMAS NMR experiment brings further insight.

Table 1.Fitted build-up time (TDNP) and corresponding stretching coefficient ( $\beta$ ) from indirect DNP ${ }^{27} \mathrm{Al} N M R$ spectra, for each aluminum in pure $\mathrm{Y}$ zeolite, $\gamma-\mathrm{Al}_{2} \mathrm{O}_{3}$ zeolite and $\mathrm{Y} / \gamma-\mathrm{Al}_{2} \mathrm{O}_{3}$ extrudates. The calcination procedure is similar for all samples.

\begin{tabular}{|c|c|c|c|}
\hline & & $\mathbf{T}_{\mathrm{DNP}} / \mathbf{s}$ & $\boldsymbol{\beta}$ \\
\hline Y zeolite & $\mathrm{AlIV}^{\mathrm{Zzeo}}(\sim 64 \mathrm{ppm})$ & $2.0 \pm 0.1$ & $1.0 \pm 0.1$ \\
\hline \multirow[t]{2}{*}{ Alumina } & Alvalu ( $70 \mathrm{ppm})$ & $4.9 \pm 0.9$ & $0.63 \pm 0.07$ \\
\hline & Alvialu ( 14 ppm) & $4.3 \pm 0.5$ & $0.69 \pm 0.06$ \\
\hline \multirow[t]{3}{*}{ extrudate } & $\mathrm{Al}^{\mathrm{IV}}$ alu $(\sim 70 \mathrm{ppm})$ & $4.8 \pm 0.5$ & $1.0 \pm 0.12$ \\
\hline & $\mathrm{Al}^{\mathrm{IV}} \mathrm{Zeo}(\sim 64 \mathrm{ppm})$ & $6.9 \pm 0.7$ & $0.95 \pm 0.09$ \\
\hline & Alvialu $(\sim 14$ ppm) & $5.5 \pm 0.2$ & $0.93 \pm 0.03$ \\
\hline
\end{tabular}

\section{Nature of the zeolite-binder interface}

${ }^{27} \mathrm{Al}-\left\{{ }^{29} \mathrm{Si}\right\} \mathrm{J}-\mathrm{HMQC}$ MAS NMR reveals scalar couplings (i.e., chemical bounds) between ${ }^{27} \mathrm{Al}$ and ${ }^{29} \mathrm{Si}$ nuclei in a 2D correlation spectrum and can therefore bring important information to clarify the nature of the zeolite/binder interface provided enough sensitivity is achieved. Here, even at microwave OFF, the presence of radicals (decreasing the ${ }^{27} \mathrm{Al}$ relaxation times) associated with a low temperature $(\sim 100 \mathrm{~K})$ and a high permanent field (18.8 T) provides enough sensitivity and is less time consumming, that would not have been possible at RT on a lower magnetic field spectrometer for reasonable experiment time. Figure 3 shows a correlation map between a tetrahedral zeolitic aluminum (65 ppm, viz. Figure $1 \mathrm{a}$ and Figure $1 \mathrm{~b})$ and a $\mathrm{Q}^{4}$ silicon (-101 ppm), i.e. tetrahedral silicon bound to $\mathrm{n}$ aluminum atoms in zeolite $\mathrm{Y} .{ }^{29} \mathrm{Si}$ MAS NMR spectra are presented in SI (Figure S5a and Figure S5b). Both spectra display resonances in the region of Q4(nAl) species (i.e. tetraedral silicon, connected to $\mathrm{n}$ aluminum atoms). Another correlation appears between a tetrahedral aluminum from the alumina binder $(75 \mathrm{ppm})$ and again a $\mathrm{Q}^{4}$ silicon $(\sim-100 \mathrm{ppm})$ in zeolite Y. The latter is due to an interaction between terminal zeolitic silanols with tetrahedral aluminum from the binder. This implies that tetrahedral aluminum from the binder are chemically bound to zeolitic silicon atoms. This confirm our 
previous hypothesis of a chemical reaction between the alumina binder and the zeolite, assumed to take place during the calcination when the pseudobohemite precursor is transformed in $\gamma-\mathrm{Al}_{2} \mathrm{O}_{3} .{ }^{11}$ This also agrees with the spatial organization proposed by the $\mathrm{T}_{\mathrm{DNP}}$ derived from the DNP ${ }^{27} \mathrm{Al}\left\{{ }^{1} \mathrm{H}\right\}$ saturation recovery $\mathrm{CP}$ experiments and the presence of an ASA (amorphous silica-alumina) phase at the zeolite binder interface. ${ }^{11}$

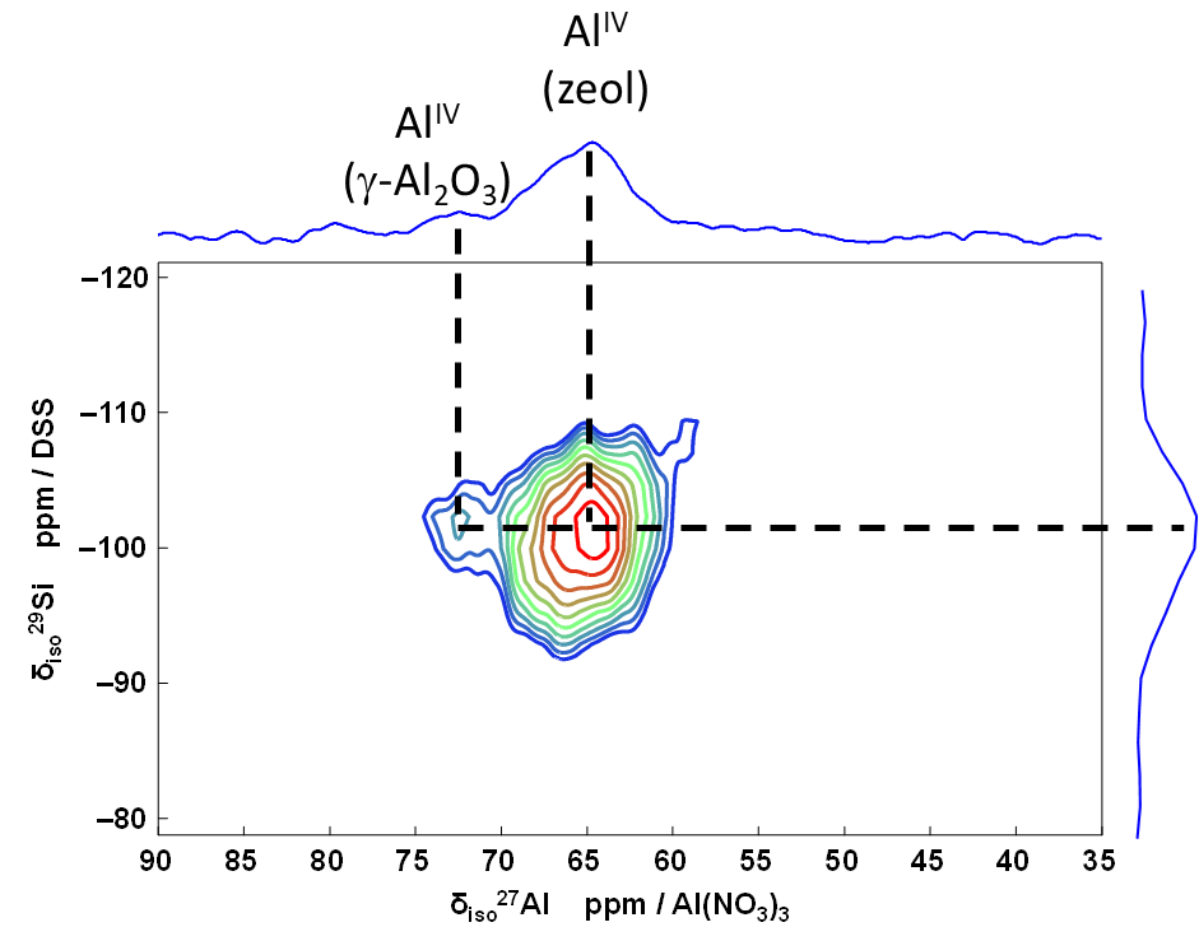

Figure $3 .{ }^{27} \mathrm{Al}-\left\{{ }^{29} \mathrm{Si}\right\} \mathrm{J}-\mathrm{HMQCspectra}$ on dehydrated extrudates.

\section{Conclusion}

We have demonstrated that zeolite catalyst forming is more than a physical mixture between a zeolite and a binder resulting in a well-dispersed zeolite active phase in, for instance, alumina. Indirect $\mathrm{Al}\left\{{ }^{1} \mathrm{H}\right\}$ DNP MAS NMR shows that the tetrahedral and octahedral aluminum in the $\gamma-\mathrm{Al}_{2} \mathrm{O}_{3}$ binder, all in close proximity with the PA agent, are polarized directly while only the zeolitic tetrahedral atoms located on the external surface of the crystals are polarized by a spin diffusion process, in line with their close proximity to the alumina. Moreover, ${ }^{27} \mathrm{Al}-\left\{{ }^{29} \mathrm{Si}\right\} \mathrm{J}-\mathrm{HMQC}$ NMR explicitly indicates that tetrahedral aluminum from the binder reacts with zeolitic $\mathrm{Si}$ located on its external surface.

Tools now exist to monitor and control atomic level features during the forming process of catalysts. They clearly indicate that in this ubiquitous manufacturing step, controlled catalyst fine-tuning, as active site creation, can take place to optimize their performances further.

Such a study, on technical bodies formed by extrusion, can also be applied to other forming processes (spray-drying, oil-dropping, pelletizing...) with different binders $\left(\mathrm{SiO}_{2}, \mathrm{AlPO}_{4}\right.$, clays...) and extended to noncatalytic processes such as adsorption on porous solids.

\section{ASSOCIATED CONTENT}

Supporting Information. XRD powder diffraction patterns of zeolite Y (normalized to $30 \%$ ) and extrudates, Y/Ext and the. Catalytic activity of pure zeolite $Y$, physical mixture of zeolite $Y$ and $\gamma$-alumina (30\% wt zeolite $\mathrm{Y}$ and $70 \%$ wt $\gamma$-alumina) and extrudates, Y/Ext. is available free of charge via the Internet at http://pubs.acs.org.

\section{AUTHOR INFORMATION}

\section{Corresponding Author}


*iean-pierre.gilson@ensicaen.fr

\section{Author Contributions}

The manuscript was written through contributions of all authors. All authors have given approval to the final version of the manuscript **These authors contributed equally.

\section{ACKNOWLEDGMENT}

Honeywell UOP for funding and permission to publish. Financial support from the IR-RMN-THC Fr3050 CNRS grant is also gratefully acknowledged. We thank Dr. David Gajan for his technical support on the $800 \mathrm{MHz}$ spectrometer and for very helpful discussions.

\section{REFERENCES}

(1) Rigutto, M. S.; van Veen, R.; Huve, L. Zeolites in Hydrocarbon Processing; Elsevier B.V., 2007; Vol. 168, pp 855-913.

(2) Kulprathipanja, S. Zeolites in Industrial Separation and Catalysis;Wiley-VCH, 2010.

(3) Marcilly, C.; Decroocq, D. Acido-Basic Catalysis: Application to Refining and Petrochemistry; Éd. Technip: Paris, 2006

(4) Sheldon, R. A.; van Bekkum H. Fine Chemicals through Heterogeneous Catalysis Wiley-VCH, 2001.

(5) Ennaert, T.; Van Aelst, J.; Dijkmans, J.; De Clercq, R.; Schutyser, W.; Dusselier, M.; Verboekend, D.; Sels, B. F. Potential and Challenges of Zeolite Chemistry in the Catalytic Conversion of Biomass. Chem. Soc. Rev. 2016, 45 (3), 584-611.

(6) Vermeiren, W.; Gilson, J. P. Impact of Zeolites on the Petroleum and Petrochemical Industry. Top. Catal. 2009, 52 (9), 1131-1161.

(7) Hargreaves, J. S. J.; Munnoch, A. L. A Survey of the Influence of Binders in Zeolite Catalysis. Catal. Sci. Technol. 2013, 3 (5), 1165-1171.

(8) Mitchell, S.; Michels, N. L.; Pérez-Ramírez, J. From Powder to Technical Body: The Undervalued Science of Catalyst Scale Up. Chem. Soc. Rev. 2013, 42 (14), 6094-6112.

(9) Gleichmann, K.; Unger, B.; Brandt, A. Manufacturing of Industrial Zeolite Molecular Sieves. Chemie-IngenieurTechnik 2017, 89 (7), 851-862.

(10) Bingre, R.; Louis, B.; Nguyen, P. An Overview on Zeolite Shaping Technology and Solutions to Overcome Diffusion Limitations. Catalyst 2018, 8(163), 1-18.

(11) Lakiss, L.; Gilson, J. P.; Valtchev, V.; Mintova, S.; Vicente, A.; Vimont, A.; Bedard, R.; Abdo, S.; Bricker, J. Zeolites in a Good Shape: Catalyst Forming by Extrusion Modifies Their Performances. Microporous Mesoporous Mater. 2020, 299, 110114.

(12) Seghers, S.; Lefevere, J.; Mullens, S.; De Vylder, A.; Thybaut, J. W.; Stevens, C. V. Enhancing Zeolite Performance by Catalyst Shaping in a Mesoscale Continuous-Flow Diels-Alder Process. ChemSusChem 2018, 11 (10), 1686-1693.

(13) Shoinkhorova, T.; Dikhtiarenko, A.; Ramirez, A.; Dutta Chowdhury, A.; Caglayan, M.; Vittenet, J.; BendjeriouSedjerari, A.; Ali, O. S.; Morales-Osorio, I.; Xu, W.; Gascon, J. Shaping of ZSM-5-Based Catalysts via Spray Drying: Effect on Methanol-to-Olefins Performance. ACS Appl. Mater. Interfaces 2019, 11 (47), 44133-44143.

(14) Michels, N. L.; Mitchell, S.; Pérez-Ramírez, J. Effects of Binders on the Performance of Shaped Hierarchical MFI Zeolites in Methanol-to-Hydrocarbons. ACS Catal. 2014, 4 (8), 2409-2417.

(15) Espinosa-Alonso, L.; Beale, A. M.; Weckhuysen, B. M. Profiling Physicochemical Changes within Catalyst Bodies during Preparation: New Insights from Invasive and Noninvasive Microspectroscopic Studies. Acc. Chem. Res. 2010, 43 (9), 1279-1288.

(16) Bergwerff, J. A.; Van De Water, L. G. A.; Visser, T.; De Peinder, P.; Leliveld, B. R. G.; De Jong, K. P.; Weckhuysen, B. M. Spatially Resolved Raman and UV-Visible-NIR Spectroscopy on the Preparation of 
Supported Catalyst Bodies: Controlling the Formation of H 2PMo11CoO405- inside A1 $2 \mathrm{O} 3$ Pellets during Impregnation. Chem. - A Eur. J. 2005, 11 (16), 4591-4601.

(17) Jacques, S. D. M.; Di Michiel, M.; Beale, A. M.; Sochi, T.; O’Brien, M. G.; Espinosa-Alonso, L.; Weckhuysen, B. M.; Barnes, P. Dynamic X-Ray Diffraction Computed Tomography Reveals Real-Time Insight into Catalyst Active Phase Evolution. Angew. Chemie - Int. Ed. 2011, 50 (43), 10148-10152.

(18) O’Brien, M. G.; Jacques, S. D. M.; Di Michiel, M.; Barnes, P.; Weckhuysen, B. M.; Beale, A. M. Active Phase Evolution in Single Ni/Al $2 \mathrm{O} 3$ Methanation Catalyst Bodies Studied in Real Time Using Combined $\mu$-XRD-CT and $\mu$-Absorption-CT. Chem. Sci. 2012, 3 (2), 509-523.

(19) Whiting, G. T.; Nikolopoulos, N.; Nikolopoulos, I.; Chowdhury, A. D.; Weckhuysen, B. M. Visualizing Pore Architecture and Molecular Transport Boundaries in Catalyst Bodies with Fluorescent Nanoprobes. Nat. Chem. 2019, 11 (1), 23-31.

(20) Mitchell, S.; Michels, N.-L.; Kunze, K.; Pérez-Ramírez, J. Visualization of Hierarchically Structured Zeolite Bodies from Macro to Nano Length Scales. Nat. Chem. 2012, 4 (10), 825-831.

(21) Lesage, A.; Lelli, M.; Gajan, D.; Caporini, M. A.; Vitzthum, V.; Miéville, P.; Alauzun, J.; Roussey, A.; Thieuleux, C.; Mehdi, A.; Bodenhausen, G.; Copéret, C.; Emsley, L. Surface Enhanced NMR Spectroscopy by Dynamic Nuclear Polarization. J. Am. Chem. Soc. 2010, 132 (44), 15459-15461.

(22) Lafon, O.; Lilly Thankamony, A. S.; Rosay, M.; Aussenac, F.; Lu, X.; Trébosc, J.; Roumazeilles, V. B.; Vezine, H.; Amoureuxa, J. P. Indirect and Direct29Si Dynamic Nuclear Polarization of Dispersed Nanoparticles. Chem. Commun. 2013, 49 (28), 2864-2866.

(23) Lee, D.; Duong, N. T.; Lafon, O.; De Paëpe, G. Primostrato Solid-State NMR Enhanced by Dynamic Nuclear Polarization: Pentacoordinated A13+ Ions Are Only Located at the Surface of Hydrated $\gamma$-Alumina. J. Phys. Chem. C 2014, 118 (43), 25065-25076.

(24) Mais, M.; Paul, S.; Barrow, N. S.; Titman, J. J. Dynamic Nuclear Polarisation Enhanced Solid-State Nuclear Magnetic Resonance Studies of Surface Modification of ?-Alumina. Johnson Matthey Technol. Rev. 2018, 62 (3), $271-278$.

(25) Schlagnitweit, J.; Tang, M.; Baias, M.; Richardson, S.; Schantz, S.; Emsley, L. Nanostructure of Materials Determined by Relayed Paramagnetic Relaxation Enhancement. J. Am. Chem. Soc. 2015, 137 (39), 12482-12485.

(26) Pinon, A. C.; Schlagnitweit, J.; Berruyer, P.; Rossini, A. J.; Lelli, M.; Socie, E.; Tang, M.; Pham, T.; Lesage, A.; Schantz, S.; Emsley, L. Measuring Nano- to Microstructures from Relayed Dynamic Nuclear Polarization NMR. J. Phys. Chem. C 2017, 121 (29), 15993-16005.

(27) Fung, B. M.; Khitrin, A. K.; Ermolaev, K. An Improved Broadband Decoupling Sequence for Liquid Crystals and Solids. J. Magn. Reson. 2000, 142 (1), 97-101.

(28) Busca, G. Chapter Three - Structural, Surface, and Catalytic Properties of Aluminas; Jentoft, F. C. B. T.-A. in C., Ed.; Academic Press, 2014; Vol. 57, pp 319-404.

(29) Narayanan, A.; Hartman, J. S.; Bain, A. D. Characterizing Nonexponential Spin-Lattice Relaxation in Solid-State NMR by Fitting to the Stretched Exponential. J. Magn. Reson. Ser. A 1995, 112 (1), 58-65.

(30) Peyron, M.; Pierens, G. K.; Lucas, A. J.; Hall, L. D.; Stewart, R. C. The Modified Stretched-Exponential Model for Characterization of NMR Relaxation in Porous Media. J. Magn. Reson. Ser. A 1996, 118 (2), 214-220.

(31) Petrov, O. V; Stapf, S. Parameterization of NMR Relaxation Curves in Terms of Logarithmic Moments of the Relaxation Time Distribution. J. Magn. Reson. 2017, 279, 29-38. 
For Table of Contents Only

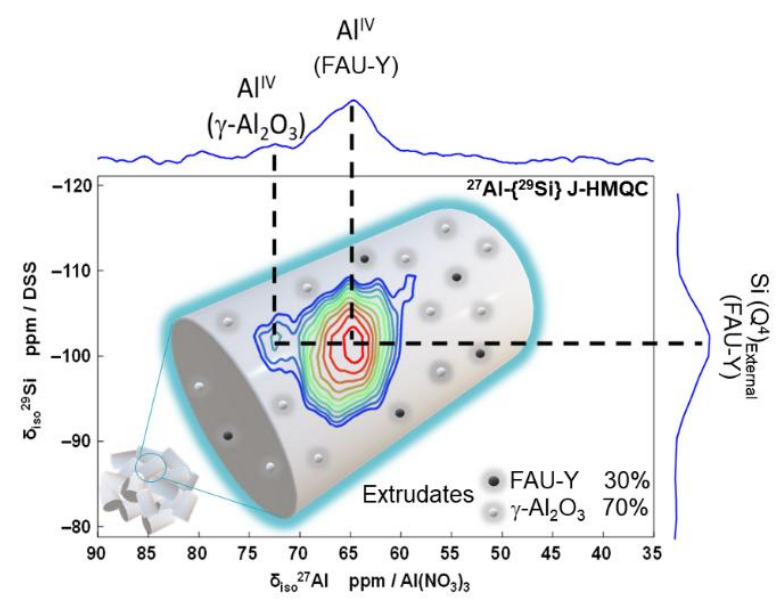

